\title{
El problema de la regionalización durante el periodo colonial y modelos de poblamiento
}

\author{
(Hipótesis para su estudio) $^{\mathrm{A}}$
}

\section{Germán Colmenares}

A raíz de las guerras de Independencia, curas desafectos al régimen republicano podían ser trasladados de sus parroquias a alguna región distante del territorio de la nueva república. Uno de ellos se quejaba amargamente de que se lo extrañaba del suelo patrio. Solo una poderosa retórica y la experiencia de los hombres que se movilizaban dentro de las filas del ejército en los escenarios de una guerra, que abarcaba el territorio de lo que iban a ser cinco naciones, podía desvanecer el sentido inmediato del arraigo parroquial o regional en una conciencia criolla. La patria del criollo, a finales del régimen colonial, no podía ser otra que el espacio concreto en el que podía resolverse su acción o su influencia, sus nexos familiares o sus negocios. Este sentimiento subjetivo del arraigo no se acompañaba todavía de imágenes de pertenencia a una comunidad imaginada mucho más amplia, en manera en la que la propia vida se imbricara en el destino colectivo de una nación.

A Escrito en máquina de escribir mecánica (18 páginas en papel carta, a espacio y medio), fechado por Germán Colmenares como "V-[19]88", contiene algunas correcciones hechas por el propio autor, y observaciones en el margen izquierdo en letra que corresponde a Hernán Lozano, el editor de la llamada "Obra Completa" de Colmenares. Estas últimas son indicaciones que en general tienen que ver más con la organización en párrafos del texto, que con el contenido. En la primera página, en la parte superior derecha hay una observación de Hernán Lozano que muestra cuánta atención ponía a los papeles que revisó y cómo realizaba grandes esfuerzos para asimilar un contenido de ciencia que en principio le era extraño, sobre todo si se trata de un texto como éste, de fondo histórico concreto, pero que incluye elaboraciones conceptuales no siempre fáciles de asimilar. "Noto cierta espontaneidad, frescura, en este artículo. Abril/91", escribe Lozano, con entusiasmo y con algo de ingenuidad, recién que había comenzado su trabajo de editor. Sin tratar de superponer un comentario al texto que reproducimos, se puede señalar que la intención del texto no es otra que la de "desestabilizar" una serie de nociones puramente "continuistas" bajo las cuales se ha pensado el espacio de la sociedad colonial, por relación con la organización espacial que se inicia con la sociedad revolucionaria del siglo XIX, e insistir en un hecho, este sí mucho más conocido: el anacronismo ("flagrante", lo designa Colmenares) en que se incurre cuando se proyecta el espacio nacional, aún en vías de constitución, de los siglos XIX y XX, sobre el espacio de la sociedad de los siglos XVI-XVIII, en la época de la dominación monárquica. Una crítica que Colmenares extiende al uso de la noción de "espacio fragmentado" para la sociedad colonial, característica que se deduce en general de la observación, también anacrónica, sobre el funcionamiento del mercado, del cual se espera tal vez que funcione de la manera como lo supone la teoría económica neoclásica en las sociedades llamadas "nacionales modernas". 
La creación de estas imágenes fue anterior en todo caso a todos los proyectos políticos capaces de plasmar un orden institucional homogéneo sobre regiones heterogéneas y sobre intereses materiales, si no divergentes, al menos disociados unos de otros. El poder de estas mismas imágenes opera con tal fuerza en nuestra visión de la colonia que, inadvertidamente, amalgamamos construcciones y experiencias históricas divergentes como un antecedente necesario de la territorialidad de la nación. Este procedimiento parece justificarse solo por la sucesión de entes administrativos a los que una ficción política atribuye una continuidad.

Resulta así que la historia del periodo colonial, construida desde una perspectiva del territorio nacional, es un anacronismo flagrante. Estas versiones tienden a atribuir al gobierno español y a la política imperial unos efectos parecidos a los de la intensa preocupación legislativa e institucional que caracterizó el siglo XIX. El periodo colonial resultaba ser así el progresivo montaje de unas instituciones jurídico - administrativas sobre una realidad caótica que dejaba el periodo anterior a la conquista. La síntesis de esta historia institucional ni siquiera reparaba en el problema de los desajustes de una sociedad preexistente con respecto al sistema que las instituciones iban erigiendo. La historia colonial se concebía en cierta manera como un teatro en el que el libreto eran las famosas leyes de Indias. Ellas iban señalando los papeles sociales y políticos de los actores (funcionarios, españoles, criollos, indios, esclavos y castas), venciendo resistencias obstinadas, moldeando a una sociedad dentro de un orden. La historia patria exigía que estos esfuerzos institucionales desembocaran en una unidad a la que solo podía hacerle falta el aliento heroico que la animara como una nación. Por esta razón todas las contradicciones, todos los conflictos, la dispersión de los espacios y la multiplicidad de las culturas deberían subsumirse armónicamente en las previsiones de las leyes de Indias. La voluntad política expresada en ellas se desarrollaba en una temporalidad lineal y en la abolición de la dispersión caótica de los espacios. La temporalidad lineal aseguraba un tránsito entre la procesión solemne de presidentes de la Audiencia y de los virreyes y la de los gobernantes republicanos. Este sentido de la continuidad se proyectaba también sobre el espacio, reduciéndolo a su acepción de jurisdicción administrativa.

Si nos salimos de los marcos de la historia institucional para construir una historia social y una historia económica, las temporalidades y los espacios recobran su aspecto múltiple y caótico. El marco adecuado para la historia económica o una historia social no puede ser la Nueva Granada como ente jurídico administrativo. El espacio fragmentario como unidad de análisis no solo responde a realidades económicas y sociales sino a la experiencia íntima de los actores sociales, a sus posibilidades de desplazamiento a las distancias reales impuestas por la geografía y por las precarias condiciones de la época. 
La fragmentación del espacio colonial podría verse también como la antítesis de la unidad del espacio nacional. Se pasaría así de la ficción de un espacio común, [compartida] tanto [por] una historia colonial como por una historia nacional, al tema de una gradual integración de espacios regionales que, en su conjunto, irían a constituir el espacio nacional. Pero las cosas no ocurren de manera tan sencilla. No debe olvidarse que la generalidad de las relaciones económicas en las regiones en Hispanoamérica, estaban dadas dentro del marco de un Imperio. La coherencia entre las regiones debe pensarse, entonces, no como antecedente de una formación nacional, sino como el producto de especializaciones y de subordinaciones de una política imperial. Desde este punto de vista resulta natural agrupar las provincias de Panamá, de Cartagena y de Santa Marta, para dar cuenta de relaciones múltiples dentro de la cuenca del Caribe, en las ferias de Cartagena y de Porto Belo, en el tráfico de esclavos y el abastecimiento de las flotas. Las conexiones de Pasto con la Audiencia de Quito no eran solo de carácter administrativo. Su afinidad con la sierra del norte del Ecuador era mucho más cercana que con el resto de la provincia de Popayán. En ambas regiones, a diferencia del resto del territorio de la Nueva Granada, la adscripción de mano de obra a las haciendas se operaba mediante el peonaje por deudas. En cuanto al resto de la Gobernación de Popayán, ella constituye una unidad de análisis cuyos nexos con Santafé eran muy tenues. Los obrajes de Quito abastecían de géneros burdos sus cuadrillas de esclavos y sus comerciantes prolongaban la carrera de Indias con esclavos hasta Quito. La provincia de Antioquia constituyó por mucho tiempo una frontera minera y solo a finales del siglo XVIII sus comerciantes sentaron reales en Honda. La provincia de Pamplona debería estudiarse preferiblemente en sus conexiones con la región de Mérida y de Maracaibo. En cuanto al Nuevo Reino, con sus núcleos urbanos de Santafé, Tunja, Vélez, Muzo y Tocaima, debería verse como una realidad separada del Valle central del Magdalena. Durante gran parte del periodo colonial esta fue una región periférica que gravitó indistintamente alrededor de Popayán y del Nuevo Reino.

La antítesis entre región y nación es una antítesis falsa sencillamente porque las regiones colombianas se construyeron simultáneamente con la nación. Ninguna de las regiones que hoy podemos identificar tenía una entidad siquiera aproximada a la actual a comienzos del siglo XIX. En ese entonces sólo pueden reconocerse núcleos urbanos aislados, con una jurisdicción teórica, que encontraba toda clase de contradicciones en el poblado más próximo (Cartagena - Mompox - Santa Marta, Tunja Vélez - Pamplona -, Popayán - Cali, etc. $)^{\mathrm{B}}$. Además, la población de estos claustros

B En la parte superior de la página, escrito en color azul con tinta de "esferográfico", en la letra de Germán Colmenares, y junto a un asterisco, puede leerse: “* Esta contradicción venía primordialmente por la disputa de recursos. La distancia entre un núcleo urbano y otro podía medirse por los recursos 
coloniales alcanzaba apenas una densidad de uno o dos habitantes por $\mathrm{Km}^{2}$, dejando así casi completamente deshabitadas las cuatro quintas partes del territorio de cualquier presunta región.

La fragmentación del espacio colonial no debe enfocarse como el origen de la región. A lo sumo, la región no es sino un subproducto de las reflexiones sobre la unidad nacional. En sus inicios, la colonia debe entenderse en sus propios términos, como la coexistencia de dos repúblicas, la república de los españoles y la república de los indios. La república de los españoles era por antonomasia, la ciudad con sus jerarquías, sus privilegios corporativos, sus términos y jurisdicción.

La república de los indios no era un concepto de igualdad con respecto a la república de españoles sino, por el contrario, un concepto de subordinación. Debía existir una república de indios como sustento de la otra. Se establecía así una jerarquía natural entre el poblamiento de los españoles y los poblamientos indígenas.

A partir de la conquista el espacio se jerarquizó en función de la importancia de los núcleos urbanos. Las ciudades tenían un significado patrimonial con respecto a su entorno rural, su jurisdicción o sus términos. Este patrimonialismo enfrentaba unas ciudades a otras, sin que pudiera establecerse entre ellas nexos de subordinación. A lo sumo, las villas debían admitir a regañadientes esta subordinación, porque ellas cercenaban parte de los términos de una antigua ciudad.

Evidentemente, la sede de la Audiencia o la cabeza de una gobernación tenía ventajas sobre las demás ciudades. Pero eran ventajas permanentemente discutidas o que no tenían en sus orígenes un primado de importancia. Por eso el primer presidente de la Audiencia, Venero de Leiva, proponía que este cuerpo funcionara indistintamente en Santafé y en Tunja.

Durante los siglos XVI y XVII la autonomía de las ciudades se fundaba en sus privilegios patrimoniales. Cada una tenía sus propias justicias ordinarias y rechazaba sistemáticamente los jueces de comisión cuyos emolumentos tenían que provenir de multas y penas de cámara entre las partes que litigaban. La justicia ejercida por los alcaldes ordinarios era en muchos casos un arbitraje en el seno de la red abigarrada de parentescos. Ningún vecino se sometía de buen grado a las decisiones tomadas por una jurisdicción extraña y las apelaciones ante instancias superiores se demoraban años y en muchas ocasiones iban abultando los expedientes sin que se tomara jamás una decisión.

Los privilegios corporativos de las ciudades tendían a crear una inercia en la que resultaba supremamente difícil la aparición de nuevos núcleos urbanos que rivalizaran con el antiguo centro. Esta situación se mantuvo, con una sola excepción, hasta mediados del siglo XVIII, cuando en diferentes partes y por diferentes razones

necesarios a su sustento. La extensión que convenía a una jurisdicción era aquella que se estimaba indispensable para el sustento de sus vecinos". 
surgieron nuevos poblamientos o se promovieron los pueblos de indios a la calidad de "parroquias de españoles".

Los nuevos poblamientos urbanos y semiurbanos comenzaron a romper las jerarquías urbanas coloniales de una manera diferente en muchas partes y con ellos se inició un esbozo de regionalización. El proceso no fue uniforme en todas partes. Puede decirse que, en el curso de la segunda mitad del siglo XVIII, se crearon los modelos básicos de poblamientos ulteriores a todo lo largo del siglo siguiente.

Debe, sin embargo, considerarse primero un caso temprano de poblamiento que rompía la dicotomía de la república de los españoles y la república de los indios. Este esquema se había intentado desde muy temprano procurando poblar a los indígenas en agrupaciones nucleadas, a la manera de los establecimientos urbanos españoles. Los indígenas resistieron a estas medidas casi por más de medio siglo y solo a finales del siglo XVI, cuando la población indígena había sido diezmada en forma abrumadora y en la vecindad de las comunidades indígenas se habían multiplicado las haciendas de los españoles, consistieron en poblarse. Los pueblos de indios, congregados en torno a capillas doctrineras y a una plaza central, tuvieron importancia en los altiplanos de Santafé, Tunja, Pasto y en las jurisdicciones de Vélez y Pamplona. En estas últimas, sin embargo, surgió tempranamente una alternativa al pueblo de indios. Esta alternativa eran las parroquias de blancos de las cuales aparecieron sucesivamente San Gil en 1620, Girón en 1631 y Socorro en 1668. Estas fundaciones, a diferencia de los pueblos de indios, pretendían a todos los privilegios corporativos de que gozaban las ciudades.

Entre estos privilegios se contaban los términos de una jurisdicción propia, tener sus propias justicias, escribano público y de cabildo y los oficios municipales que correspondían a cada una de las varas del cabildo. Cada uno de estos poblamientos tenía que litigar y ganar estos privilegios en oposición abierta de las antiguas cabeceras, las ciudades de Vélez y Pamplona. San Gil, por ejemplo, solo vio confirmada su erección por parte de la Corona española en 1664 y tuvo que sostener un largo pleito con Socorro por la delimitación de sus términos respectivos. La creación de Girón fue discutida simultáneamente por Vélez y Pamplona. Esta última alegaba que algunas de las encomiendas de los vecinos estaban ubicadas en los términos que pretendía la nueva población. Durante el siglo XVIII estas parroquias alcanzaron el título de villas, lo cual a su turno les permitía extender su influencia a otras parroquias.

No hay duda de que la obtención de privilegios corporativos, si bien no situaba en pie de igualdad a estas nuevas parroquias con los antiguos centros señoriales, al menos les procuraba una relativa independencia. El clima social y político de estos nuevos centros urbanos difería también radicalmente de los centros más antiguos, asentados originalmente en la sujeción indígena y en la extorsión de su trabajo. La presencia de mestizos y de blancos pobres favorecía la aparición de actividades económicas diferentes a la hacienda señorial y la ausencia de trabajo servil procuraba una distribución de la tierra más equitativa. No es un azar que en estas condiciones se 
hayan visto contrariadas por la política de los últimos borbones al "estancar" la distribución de tabaco y limitar las siembras y que esto hay producido una insurrección popular de vastas proporciones.

Pero también los pueblos de indios de los altiplanos de Tunja y Santafé sufrieron, aunque tardíamente, una transformación radical. A mediados del siglo XVIII el visitador Verdugo y Oquendo encontraba que, en todos los pueblos, al tiempo que la población indígena original sometida a un tributo estaba prácticamente extinguida, había crecido una numerosa población mestiza. En una sociedad de órdenes y privilegios definidos por la ley, la situación de los mestizos era más que ambigua. En teoría eran hombres libres, es decir no sometidos al tributo, pero en la práctica sufrían restricciones. No podían, por ejemplo, concertar a los indios o servirse de ellos en las labores agrícolas. En las ciudades, eran un elemento mal visto, una población flotante de vagos y desocupados y una fuente potencial y temida de conflictos. Muchos se habían agregado a las haciendas, en condiciones tan precarias que no deberían distinguirse de la de los indígenas agregados, a menos de ser promovidos a capataces o calpizques. La mayoría, sin embargo, gravitaba en torno a los pueblos de indios y lograba tomar tierras de los resguardos en arriendo. Según los visitadores esto contribuía todavía más a la degradación de los indios puesto que rara vez les pagaban los arrendamientos y cuando los pagaban lo hacían con aguardiente.

En 1777 y 1778 el criollo Francisco Antonio Moreno y Escandón, que desde 1759 había ido ascendiendo los escalones del poder en el servicio de sucesivos virreyes y que desde 1770 ocupaba uno de los cargos más altos a los que podía aspirar un criollo: la Fiscalía de la Audiencia, emprendió una de las reformas más sustanciales y debatidas al generalizar la supresión de los resguardos iniciada por Verdugo y Oquendo en 1755. Estas supresiones fueron posibles mediante el traslado, a veces violento, de parcialidades indígenas ya muy reducidas para refundirlas con otras. De esta manera se liberaban tierras que, según el proyecto de Moreno, debían rematarse entre los mestizos. De esta manera muchos pueblos de indios fueron convertidos en parroquias de "blancos". Como se ha visto en el caso de los poblamientos de las jurisdicciones de Vélez y de Pamplona, esta era una promoción que aseguraba al menos un mínimo de vida política autónoma. El proceso fue completado por leyes republicanas que erigieron las parroquias en muchos municipios.

La transformación de sociedades indígenas en sociedades campesinas desde mediados del siglo XVIII fue un proceso confinado a ciertas zonas del país. Por esta razón, el proceso que acabamos de esbozar no es un modelo único. Precisamente por esta circunstancia podría servir como patrón de referencia para juzgar la novedad de otros modelos. Algo de esto he intentado en dos artículos recientes que se refieren al valle del Cauca y a la provincia de Cartagena ${ }^{\mathrm{C}}$.

C El autor se refiere sin duda a "Castas, patronos de poblamiento y conflictos sociales en las provincias del 
El punto esencial de contraste de estos dos modelos con respecto a los que se han descrito para los altiplanos y para Santander, reside en que se trataba de zonas en las cuales predominaba la esclavitud. Surge entonces la pregunta obvia de su tránsito hacia sociedades campesinas.

Muy temprano, en el siglo XVI, Cieza de León observaba el despoblamiento del valle del Cauca. Hacia 1580 el puerto de Buenaventura había perdido importancia debido al aniquilamiento de los indígenas de la cordillera occidental que servían como tamemes o cargueros de las mercancías. La escasez de la mano de obra condicionó la aparición de vastos latifundios en los cuales pastaban ganados prácticamente cimarrones. Esta situación cambió con el surgimiento de una nueva frontera minera en el Pacífico que atrajo una abundante mano de obra esclava a partir de 1680. La necesidad de abastecer reales de minas en el Chocó y en la región del Raposo estimuló la progresiva aparición de haciendas en el valle del Cauca. Estas haciendas, que solían pertenecer también a los mineros, aprovecharon la mano de obra esclava excedentaria de las minas. De esta manera se creó un complejo económico de haciendas y minas como actividades complementarias de los mismos empresarios.

Si bien la presencia de grandes haciendas dedicadas al cultivo de la caña, a la ganadería y a algunos cultivos de pan coger fue dominante en el valle del Cauca, no puede ignorarse la presencia creciente, en la segunda mitad del siglo XVIII, de pequeños propietarios, a veces blancos pobres o mulatos y mestizos. Las haciendas, servidas por esclavos, no acogían en general, a esta población. Por esta razón se crearon núcleos de población que buscaron permanentemente su reconocimiento para adquirir privilegios corporativos como parroquias o villas. Esta situación está ilustrada de manera dramática por el caso de Quilichao, una concentración de blancos pobres y de mulatos que se dedicaban a vender aguardiente y algunas mercancías a los esclavos que los grandes señores de Popayán mantenían en sus minas de Caloto. Pese a la oposición de estos grandes señores, Quilichao prosperó y hasta llegó a obtener momentáneamente el título de villa. De una manera parecida Llanogrande (hoy Palmira), trató de adquirir su autonomía a expensas de Buga erigiéndose en villa en los primeros momentos de la revolución de independencia. Con la reconquista española perdió esta categoría pero la recobró después bajo la presidencia del general Santander.

Otras poblaciones como Tuluá, Cerrito, Florida, Candelaria, La Unión, etc., tuvieron que luchar también para adquirir un rango municipal en oposición abierta a

Cauca, 1810-1830”, en La Independencia. Ensayos de historia social, editado por Germán Colmenares et al. (Bogotá: Instituto Colombiano de Cultura, 1986); y "El tránsito a sociedades campesinas de dos sociedades esclavistas en la Nueva Granada: Cartagena-Popayán, 1750-1850". Primer Congreso Internacional de Historia de la Universidad Interamericana de Puerto Rico. San Juan, en máquina de escribir, agosto de 1987. Pero el texto fue escrito varios meses atrás, en mayo de ese año según Hernán Lozano, pues Colmenares hizo su presentación preliminar en dos oportunidades anteriores a la de Puerto Rico. Huellas, Revista de la Universidad del Norte, publicó la versión "puertorriqueña" de este texto. 
su antigua cabecera o a la de poderosos terratenientes. A veces, los intereses de estos podían coincidir hasta cierto punto con el de las nuevas concentraciones puesto que requerían una mano de obra abundante para cultivos como el del tabaco. En el largo plazo, además, estos intereses comunes se vieron reforzados por la decadencia de la institución esclavista. Esta decadencia puede comprobarse en el precio mismo de los esclavos, cuya curva descendió uniformemente desde comienzos del siglo XVIII hasta mediados del siglo XIX. Este descenso ilustra la paulatina sustitución de mano de obra esclava en las haciendas por mano de obra libre, obtenida merced a una participación de pedazos de tierra por parte de grandes terratenientes.

Puede decirse que, en comparación con la provincia de Cartagena, otro epicentro esclavista, la urbanización del valle del Cauca fue intensa y que en el curso del siglo XIX los pueblos nuevos alcanzaron, en su conjunto, una importancia equivalente a la de los antiguos asientos urbanos. En Cartagena, la hacienda tenía orígenes más antiguos que en el valle del Cauca. Como se ha visto, en este último la hacienda creció subsidiariamente a las empresas mineras. En Cartagena, en cambio, estuvo ligada al abastecimiento de las flotas españolas y se vio favorecida por el hecho de que el puerto tuviera privilegios en la trata de esclavos. Hasta el siglo XVIII estas haciendas esclavistas se ubicaban en las cercanías de Cartagena. En el siglo XVIII se experimentó una considerable expansión de la frontera agraria con fundaciones de pueblos y el establecimiento de enormes hatos ganaderos. La erosión del sistema esclavista fue también más temprana en Cartagena [de Indias] puesto que ese sistema estaba ligado a la existencia de la trata. Al decaer esta a mediados del siglo XVIII, era natural que se debilitara la hacienda esclavista tradicional de la zona. Curiosamente, esto se ha visto como un proceso de enfeudamiento puesto que, a finales del siglo XVIII, los hatos ganaderos aparecían como más importantes que las haciendas esclavistas. En realidad lo que había ocurrido era que la ampliación de la frontera agraria había dado como resultado la aparición de estos nuevos hatos cuya extensión pesaba más que la de las viejas haciendas esclavistas.

La extensa provincia de Cartagena vio también aparecer, al tiempo con los hatos, nuevos poblamientos. En contraste con lo que ocurría en el valle del Cauca, aquí la población de blancos libres, libertos, mulatos y mestizos andaba muy dispersa. Por eso, cuando en 1774 Don Antonio de la Torre y Miranda emprendió la tarea de reducir a poblado a los habitantes de la provincia, se encontró con que nada menos que la tercera parte de la población (unas 40 mil personas) andaba poco menos que enmontada o, como se decía en la Costa, "arrochelada". Las resistencias de estas gentes a poblarse se ven muy claramente en el informe que rindió trece años más tarde el padre Joseph Palacios de la Vega. Según este informe, las gentes continuaban arrocheladas en las márgenes de los ríos San Jorge, el Cauca y el Nechí.

Aunque el fenómeno de poblaciones que se marginaban de los rígidos esquemas de la sociedad colonial y que buscaban zonas de refugio fuera más general en la pro- 
vincia de Cartagena, no hay duda de que el mismo fenómeno se reprodujo, aunque en escala menor, en el otro epicentro esclavista, la gobernación de Popayán. Pero aquí, a diferencia de la Costa, hubo un esfuerzo mayor para obtener el reconocimiento legal de los nuevos poblamientos.

\section{III}

En conclusión, para el periodo colonial tal vez sea incorrecto hablar de regiones, si por esto se entiende la caracterización de una fisonomía diferenciada que solo podía surgir de redes urbanas y semiurbanas. Faltan, en todo caso, estudios sistemáticos sobre poblamiento que permitan caracterizar ese vacío en el que nos encontramos cuando tratamos de encarar el surgimiento de sociedades campesinas. Es muy probable que los modelos que hemos tratado de caracterizar para la segunda mitad del siglo XVIII hayan tenido variantes en otras zonas del país durante la primera mitad del siglo XIX. En este sentido, podría generalizarse un principio según el cual la independencia de España no logró alteraciones radicales con respecto a la situación relativa de los individuos frente al sistema político. En revancha, todo el sistema de prelaciones de los centros urbanos que había dominado durante la colonia se vio alterado por el régimen republicano. Antes que en los individuos, el principio de soberanía popular vino a radicarse en los "pueblos" (casi en el sentido de núcleos urbanos), de la misma manera que los privilegios patrimoniales se habían asignado, en el siglo XVI, a la "república de españoles".

La percepción de una falta de coherencia territorial durante la colonia ha ido encaminando los estudios históricos a hacer énfasis en torno a redes comerciales que, aunque aparezcan desdibujadas a primera vista, debían apuntar hacia una integración ulterior. El periodo de las conquistas de la primera mitad del siglo XVI se desarrolló sobre espacios múltiples que se traslapaban unos a otros. Podía reconocerse el paso anterior de una hueste pero su destino fatal se perdía, los exploradores entrecruzaban sus caminos, caminos ciegos, de los cuales se entreveía el origen pero se desconocía el término. Los conquistadores seguían la ruta de los intercambios indígenas, del oro, de la sal, de la orfebrería o de la coca. Más tarde, con la encomienda y con el tributo, no solo se apropiaron los excedentes de las economías indígenas sino también de los circuitos de intercambio. Las mantas de Tunja de vara y sesma que podían valer cuatro tomines en los altiplanos se vendían a peso y a peso y medio en el triángulo minero de Supía, Marmato y Quiebralomo.

Había, por otro lado, desde comienzos de la ocupación española, una penetración de los géneros europeos de los que los nuevos ocupantes no podían prescindir. Las redes de este comercio se prolongaban desde sitios conspicuos como Cartagena, Porto Belo, Guayaquil, Santa Marta, Riohacha y Maracaibo, y trazaban rutas consabidas a lo largo de arterias como el Magdalena, el Cauca, el Zulia, cuando no las rutas del 
contrabando por el Atrato o el paso del Adelantado. Luego, había circuitos internos de corto alcance para los productos de la tierra que ligaban regiones especialmente aptas para la agricultura o dotadas de una cierta densidad demográfica con centros mineros y comerciales. Sin tener minas en su territorio, el Nuevo Reino podía traer el oro de Pamplona, de Venadillo, de Cartago, y aun de Cáceres, San Jerónimo, Remedios y Zaragoza, gracias a sus graneros en el valle de Sáchica o a sus menestras de todo tipo.

Trátese de un circuito o del otro, del abastecimiento de ropas de Castilla y de esclavos negros, o de su contrabando, tal vez mucho más cuantioso, o de los circuitos locales que iban conformando claustros relativamente homogéneos, lo que vivificaba todo ese trajín era la expectativa del oro. La economía del oro marcó una huella profunda en muchas regiones de la Nueva Granada. Su impronta duró más de tres siglos y ella afectó, desde los inicios de la conquista, las relaciones entre conquistadores y conquistados. El oro construyó espacios míticos e imaginarios. Aun en el tercer decenio del siglo XVII, cuando habían cesado las entradas en territorios ignotos, y por cerca de tres generaciones las gentes se habían afincado de tal manera que su propio lugar en el universo ofrecía la fijeza de su propia inmovilidad, Fray Pedro Simón, al subrayar la radical novedad del Nuevo Mundo, podía figurarse una geografía fantástica, en la cual vivían hombres cuyas orejas arrastraban por el suelo u otros que podían dormir debajo del agua, o aun otros que se sustentaban apenas con los olores, además de gigantes y pigmeos. No es de extrañar que esta sed de oro haya creado esa bruma de violencia que alimentaba una economía política del terror, que Michael Taussig invita a explorar como un espacio de la muerte. El oro no solo tocaba con su gracia vivificante el comercio, sino que la codicia que despertaba moldeó la relación colonial clásica entre conquistadores y conquistados, influyó en la manera como se organizó la extorsión de los excedentes indígenas a través del tributo, introdujo relaciones de esclavitud y constituyó el motor del poblamiento de zonas inhóspitas.

Cali, V-88 